\title{
USING COST OBSERVATION TO REGULATE A MANAGER WHO HAS A PREFERENCE FOR EMPIRE-BUILDING*
}

\author{
by \\ ANA PINTO BORGES \\ NIDISAG - Núcleo de Investigação do Instituto Superior de Administração e Gestão \\ JOÃO CORREIA-DA-SILVA \\ CEF.UP and Faculdade de Economia, Universidade do Porto
}

\begin{abstract}
We study regulation of a manager who has a preference for empire-building (high output), in the presence of moral hazard (unobservable effort) and adverse selection (unobservable productivity). We find that the optimal contract is linear in cost, being composed by a fixed payment plus a partial cost-reimbursement. The preference for higher output reduces the manager's tendency to announce that her productivity is low, allowing a more powered incentive scheme (a lower fraction of the cost is reimbursed), which alleviates the problem of moral hazard.
\end{abstract}

Keywords: Procurement, Regulation, Cost reduction, Empire-building, Adverse selection, Moral hazard.

JEL Classification Numbers: D82, H42, H51, I11.

\footnotetext{
* We are deeply grateful to Didier Laussel for useful comments and suggestions. We thank Andrés Carvajal, David PérezCastrillo, Inés Macho-Stadler, Nuno Sousa Pereira, Rabah Amir, and participants in the $2^{\text {nd }}$ Meeting of the Portuguese Economic Journal, the II Economic Theory Workshop in Vigo, the XXVIII Jornadas de Economía de la Salud at Salamanca, Doctoral Workshops at U. Porto and U. Montpellier, the 2008 Calculus of Variations and Applications Conference in Lisbon and the 2009 EEA Congress in Barcelona. Ana Sofia Borges (anaborges@isag.pt) thanks Fundação para a Ciência e Tecnologia for financial support (Ph.D. scholarship). João Correia-da-Silva (joao@fep.up.pt) acknowledges support from CEF.UP and research grant PTDC/ECO/66186/2006 from Fundação para a Ciência e Tecnologia and FEDER.
} 


\section{Introduction}

Regulation of a firm under asymmetric cost information has been the subject of intensive research, following the works of Baron and Myerson (1982), Baron and Besanko (1984), Guesnerie and Laffont (1984), Maskin and Riley (1984) and Laffont and Tirole (1986). In this literature, it is assumed that the managers of the firms maximize profit net of the disutility of effort. This is a restrictive assumption, since some economists have questioned the validity of the profit-maximization hypothesis (see Baumol (1958, 1959, 1977), Williamson (1963), Marris (1964), Monsen and Downs (1965), Wilson (1989), Mueller (2003), and many others). Recent empirical evidence of deviations from profit-maximization was provided by Chetty and Saez (2005) and by Brown, Liang and Weisbenner (2008), who studied the response of corporations to the 2003 dividend tax cut in the USA.

There are two main justifications for the observed deviations from profit-maximization. One stresses the complexity of the managerial decision processes and the separation of ownership and management. Another focuses on the multiplicity of individual motivations, which include salary, security, status, power, prestige, social service and professional excellence (Niskanen, 1971; Brehm and Gates, 1997; Prendergast, 2007). For both reasons, it is very difficult to align the individual goals of the managers with those of the organization. Another line of research is based on the observation that a firm may increase its profits by deviating from the profit-maximizing behavior if this deviation induces a more favorable behavior by others (Fershtman and Judd, 1987; Sklivas, 1987). ${ }^{1}$

Perhaps the most common deviation from profit-maximization is a bias toward empirebuilding (Donaldson, 1984; Jensen, 1986, 1993), which typically takes the form of a preference for higher output and revenue. ${ }^{2}$ The empire-building bias has been increasingly considered in theoretical models (Stulz, 1990; Hart and Moore, 1995; Harris and Raviv, 1996; Li and Li, 1996; Zwiebel, 1996; Arya, Baldenius and Glover, 1999; Kanniainen, 2000), where managers are assumed to obtain private benefits from control (Grossman and Hart, 1988), which are either proportional to investment (Hart and Moore, 1995), or to the gross output from investment (Stulz, 1990).

\footnotetext{
${ }^{1}$ Fershtman and Judd (1987) and Sklivas (1987) have shown that, in a Cournot oligopoly, owners should give their managers incentives for sales, and not only for profits. The sales-maximization bias makes the firm more aggressive (responds with a higher level of production), leading to an increase in market share and profit.

${ }^{2}$ Such a bias has been found by Amihud and Kamin (1979), who gave empirical support to Baumol's $(1958,1959)$ sales-maximization hypothesis (see also the work of Marris (1963)). A reason behind this bias may be the observed relation between past revenue and current managerial compensation (McGuire, Chiu and Elbing, 1962).
} 
The empire-building tendency of managers has not been accounted for in the standard theory of regulation under asymmetric information. To fill this gap, we study procurement contracts between the government and a manager who has a preference for empire-building, and examine whether this bias leads to results that are different from those previously obtained in the literature.

In the theory of regulation and procurement, it is usually assumed that the firm (agent) is better informed about its productivity than the regulator (principal). This is common to the contributions of Baron and Myerson (1982), Baron and Besanko (1984) and Laffont and Tirole $(1986,1993)$, which were important milestones.

Baron and Myerson (1982) studied the case in which the realized cost is unobservable. In this case, the gross payment to the firm can only depend on the productivity announced by the firm (prospective payment). The firm tends to announce a low productivity, in order to receive a high payment while incurring a low cost. The procurement contract should provide incentives for the firm to announce its true productivity (by rewarding the firm for announcing a high productivity). In the setup of Baron and Besanko (1984), the regulator can, ex post, pay an auditing cost to observe (imperfectly) the firm's realized cost. The optimal scheme is to audit the firm when the reported cost is above a particular level and impose a penalty when the observed cost turns out to be low.

Laffont and Tirole (1986) have considered the case in which the regulator observes (imperfectly) the realized cost, and added the problem of moral hazard (unobservable effort). In this case, the firm tends to pretend to have a low productivity and to be making a high effort, while in fact it has a high productivity and is making a low effort. The optimal contract is shown to be linear in observed cost, being composed of a fixed payment plus a partial cost-reimbursement. Firms with high productivity produce more output, and make a greater effort. To induce this greater effort on the part of more efficient firms, the fraction of realized cost that the government reimburses to the firm is decreasing with the firm's announced efficiency. The net payment that the firm receives is also increasing with efficiency, more than compensating for the higher disutility of effort that is demanded. This is necessary for the firm to announce its efficiency truthfully. ${ }^{3}$

In this paper, we extend the model of Laffont and Tirole (1986) by allowing the manager of

\footnotetext{
${ }^{3}$ Laffont and Tirole (1986) compare their setting with the case in which the regulator is unable to observe cost (as in Baron and Myerson, 1982). If the cost is unobservable, the optimal regulatory policy is a gross transfer that depends on the firm's announced productivity (prospective payment) in such a way that the firm has no incentive to misrepresent its efficiency. The prospective payment implies no effort distortion for a given output level, contrary to the optimal incentive contract when cost is observable, in which effort is lower than optimal.
} 
the firm to have a preference for higher output, deriving utility from the difference between the output level of the firm and a reference output level. The social welfare function that the government seeks to maximize may incorporate, or not, this component of the firm's objective function (we consider both cases). ${ }^{4}$

We find that the optimal contract remains linear in cost (in spite of the preference for higher output), but depends on the strength of the preference for higher output. A stronger preference for higher output reduces the tendency of the manager to announce a low productivity (adverse selection), allowing a more powered incentive scheme (a lower fraction of the costs is reimbursed), which, in turn, alleviates the problem of moral hazard. The output level is, naturally, increasing with the strength of the preference for empire-building. And, since the cost savings associated with the effort are proportional to the output, the effort level is also increasing with the taste for empire-building. The expected social welfare increases (decreases) with the taste for empire-building whenever the expected output is higher (lower) than the reference output level.

The paper is organized as follows. Section 2 describes the model and section 3 analyzes the benchmark case of complete information. In section 4 we derive the optimal incentive scheme. Section 5 offers some concluding remarks.

\section{The model}

We consider a model of procurement in which the government (principal) offers a contract to a manager of a firm (agent) for the provision of a public good. It is an extension of the model of Laffont and Tirole (1986) in which the manager has a taste for empire-building. The technical analysis follows closely that of Laffont and Tirole (1986).

The firm produces an observable level of output, $q \in[0, \bar{q}]$, incurring a constant marginal cost, $\hat{\beta}-e$, which depends on the intrinsic marginal cost of the firm, $\hat{\beta} \in[\beta, \bar{\beta}]$, and on a cost-reducing effort level, $e \geq 0$. The intrinsic marginal cost, drawn from a uniform distribution, is the firm's private information (adverse selection). The level of effort, chosen by the firm after the contract is signed, is also unobservable by the government (moral hazard).

\footnotetext{
${ }^{4}$ Incorporating this empire-building component in the government's welfare function results in higher output and effort. Naturally, the utility of the manager increases, while the welfare of consumers decreases.
} 
The total cost is observable, and given by:

$$
C=(\hat{\beta}-e) q+\epsilon
$$

where $\epsilon$ is a random variable with zero mean describing an ex post cost disturbance.

We assume that the firm, instead of maximizing profit net of the disutility of effort (Laffont and Tirole, 1986), has also a preference for higher output. An output that is higher (lower) than a reference level, $q_{r e f}$, yields satisfaction (dissatisfaction).

The ex ante utility level of the firm is:

$$
U=E_{\epsilon}(t)+\delta\left(q-q_{r e f}\right)-\psi(e)
$$

where $E_{\epsilon}(t)$ is the expected value (with respect to $\epsilon$ ) of the net payment received from the government (the gross payment is $t+C), \delta \geq 0$ is the marginal utility of output, $q_{\text {ref }}$ is the output reference level, and $\psi(e)$, stands for the disutility of effort, with $\psi^{\prime}(e)>0, \psi^{\prime \prime}(e)>0$ and $\psi^{\prime \prime \prime}(e) \geq 0$.

The firm accepts the contract if and only if it leads to $U \geq 0 .{ }^{5}$

The social value of the public good is $S(q)$, with marginal social value strictly positive and decreasing, $S^{\prime}(q)>0$ and $S^{\prime \prime}(q)<0$, for any $q \in[0, \bar{q})$. We also set $S(0)=0$ and $S^{\prime}(\bar{q})=0$ (thus $\bar{q}$ fully covers the needs of the population).

Public good provision is financed by a distortionary mechanism (taxes, for example) so that the social cost of raising one unit is $1+\lambda$. The welfare of consumers is the social value of the public good net of the cost of providing it:

$$
S(q)-(1+\lambda) E_{\epsilon}(t+C)
$$

For the objective of the government, $W$, we consider two possibilities:

(i) the government maximizes the sum of the consumers' welfare with the utility of the firm, (this case corresponds to setting $k=0$, below);

(ii) the government maximizes the sum of the consumers' welfare with the profit of the firm, net of the disutility of effort (corresponds to setting $k=1$, below).

In fact, we also allow for intermediate cases (any $k \in[0,1]$, below).

\footnotetext{
${ }^{5}$ Observe that the only effect of the output reference level is to shift the participation constraint. It would be equivalent to consider $U=E_{\epsilon}(t)+\delta q-\psi(e)$, with participation for $U \geq \delta q_{r e f}$.
} 
The problem of the government is:

$$
\max _{q, e, t} \int_{\underline{\beta}}^{\bar{\beta}} S(q)-(1+\lambda) E_{\epsilon}(t+C)+U-k \delta\left(q-q_{r e f}\right) d \hat{\beta}
$$

subject to

$$
U \geq 0
$$

To wrap up, we make the timing of the game explicit:

1. The firm observes its intrinsic marginal cost, $\hat{\beta}$ (adverse selection);

2. The government proposes a contract which specifies an output, $q(\beta)$, and a net payment, $t(\beta, C)$, that depend on the intrinsic marginal cost that is announced by the firm, $\beta$, and on the observed total cost, $C$;

3. The firm accepts (or rejects) the contract, announces $\beta$, and chooses an unobservable level of effort, $e$ (moral hazard);

4. The government observes the output, $q$, and the total cost, $C$, and makes the corresponding payment, $t(\beta, C)+C$, to the firm.

We adapt Assumption 1 in Laffont and Tirole (1986), which guarantees that: (i) the participation constraint is binding; (ii) the second order conditions are satisfied; (iii) the optimal output is positive; and (iv) the marginal cost is positive.

\section{Assumption 1.}

(i) $\lambda>0$;

(ii) $\forall q \in[0, \bar{q}], S^{\prime \prime}(q) \psi^{\prime \prime}(0)<-(1+\lambda)$;

(iii) $S^{\prime}(0)>(1+\lambda)(\bar{\beta}-\delta)+k \delta$;

(iv) $\psi^{\prime}(\underline{\beta}-\delta)>\bar{q}$.

\section{The case of complete information}

As a benchmark case, we start by considering the case where the government is able to observe the intrinsic marginal cost, $\hat{\beta}$, as well as the level of effort, $e$.

The problem of the government is to maximize social welfare:

$$
\max _{q, e, t}\left\{S(q)-(1+\lambda) E_{\epsilon}(t+C)+U-k \delta\left(q-q_{r e f}\right)\right\}
$$


subject to

$$
U \geq 0
$$

We find that the optimal level of output, $q_{c}^{*}$, and the optimal level of effort, $e_{c}^{*}$, are decreasing functions of the intrinsic marginal cost, $\hat{\beta}$, and increasing functions of the taste for empirebuilding, $\delta$ (see Appendix A.1).

We also find that social welfare, $W_{c}^{*}$, is increasing (decreasing) with the taste for empirebuilding, $\delta$, if and only if the optimal output, $q_{c}^{*}$, is higher (lower) than the reference output, $q_{\text {ref }}$.

It is not surprising that a firm with a stronger preference for output produces more (effort also increases because the resulting cost savings are proportional to output). This effect is stronger if the government incorporates a preference for output in the social welfare function $(k=0)$. But it is still present even if the government neglects the welfare effect of the satisfaction associated with empire-building $(k=1)$, because a firm with a stronger preference for output is willing to receive a lower money transfer, and the government prefers to "pay" with output than to pay with money (to avoid the tax distortion). Notice that the welfare effect of the empire-building component disappears when $k=1$ and $\lambda \rightarrow 0$.

The welfare effect of the taste for empire-building depends on whether the firm considers that output is high (the glass is half full), implying an increase in utility, or small (the glass is half empty), implying a utility penalty. Again, even if the social welfare function does not include the satisfaction or dissatisfaction associated with empire-building, the resulting variation of the money transfer that the firm requires to participate induces an effect in the same direction but with a smaller magnitude (associated with the tax distortion). When the reference output is lower than expected output, a manager with a stronger preference for empire-building is less costly to society as a whole, because she receives in a non-monetary form a larger part of the informational rent. The opposite occurs when the reference output is higher than expected output.

\section{The optimal incentive scheme}

In this section, we consider the case in which the government is not able to observe the intrinsic marginal cost of the firm, $\hat{\beta}$, nor the effort level chosen by the firm, $e{ }^{6}$

\footnotetext{
${ }^{6}$ Before the contract is signed, the government knows the objective function of the firm, and the prior probability distribution of the efficiency parameter, $\hat{\beta}$.
} 
The government offers a contract to the firm, $[q(\beta), e(\beta), t(\beta, C)]$, specifying an output, $q(\beta)$, an effort level, $e(\beta)$, and a payment scheme, $t(\beta, C)$, which depend on the intrinsic marginal cost announced by the firm, $\beta$.

A firm with an intrinsic marginal cost $\hat{\beta}$ that announces an intrinsic marginal cost $\beta$ will choose an individually optimal level of effort, attaining an utility given by:

$$
U(\beta, \hat{\beta})=\max _{e}\left\{E_{\epsilon}\{t[\beta,(\hat{\beta}-e) q+\epsilon]\}+\delta\left[q(\beta)-q_{r e f}\right]-\psi(e)\right\} .
$$

Thanks to the Revelation Principle, we restrict the contract to be incentive-compatible. ${ }^{7}$ It must induce the firm to choose the specified effort, $e=e(\beta)$, and reveal truthfully its intrinsic marginal cost, $\beta=\hat{\beta}$ :

$$
e(\beta) \in \underset{e}{\operatorname{argmax}}\left\{E_{\epsilon}\{t[\beta,(\hat{\beta}-e) q+\epsilon]\}+\delta\left[q(\beta)-q_{r e f}\right]-\psi(e)\right\}
$$

and

$$
\hat{\beta} \in \underset{\beta \in[\underline{\beta}, \bar{\beta}]}{\operatorname{argmax}} U(\beta, \hat{\beta}) .
$$

Incentive compatibility is satisfied if and only if $V^{\prime}(\hat{\beta})=-\psi^{\prime}[e(\hat{\beta})]$ and $e^{\prime}(\hat{\beta})<1$, where $V(\hat{\beta})$ is the utility that is attainable by the firm (see Appendix A.2.1). This means that more efficient firms obtain higher utility and that the actual marginal cost, $\hat{\beta}-e$, increases with the intrinsic marginal cost, $\hat{\beta}$.

The problem of the government (solved in Appendix A.2.2) can be written as:

$$
\begin{array}{r}
\max _{q(\hat{\beta}), e(\hat{\beta}), V(\hat{\beta})} \int_{\underline{\beta}}^{\bar{\beta}} S[q(\hat{\beta})]-(1+\lambda)\left\{V(\hat{\beta})-\delta\left[q(\hat{\beta})-q_{r e f}\right]+\psi[e(\hat{\beta})]\right\}- \\
-(1+\lambda)[\hat{\beta}-e(\hat{\beta})] q(\hat{\beta})+V(\hat{\beta})-k \delta\left[q(\hat{\beta})-q_{r e f}\right] d \hat{\beta}
\end{array}
$$

subject to, for all $\hat{\beta}$,

$$
\begin{gathered}
V(\hat{\beta})=0, \\
V^{\prime}(\hat{\beta})=-\psi^{\prime}[e(\hat{\beta})], \\
e^{\prime}(\hat{\beta})<1 .
\end{gathered}
$$

\footnotetext{
${ }^{7}$ By the Revelation Principle (Myerson, 1979), given a Bayesian equilibrium of a game with incomplete information, there exists an incentive compatible direct mechanism that has an equivalent equilibrium.
} 
Let $\left\{q^{*}(\hat{\beta}), e^{*}(\hat{\beta}), V^{*}(\hat{\beta})\right\}$ denote the solution, let $C^{*}(\hat{\beta})=\left[\hat{\beta}-e^{*}(\hat{\beta})\right] q^{*}(\hat{\beta})$, and let $t^{*}(\hat{\beta})=V^{*}(\hat{\beta})-\delta\left[q^{*}(\hat{\beta})-q_{\text {ref }}\right]-\psi\left[e^{*}(\hat{\beta})\right]$.

When there is no cost disturbance, to implement the solution, it suffices for the government to: (i) ask the firm to announce its marginal cost, $\beta$; (ii) choose output $q^{*}(\beta)$; and (iii) give transfer $t^{*}(\beta)$ if $C=C^{*}(\beta)$, and $-\infty$ otherwise.

However, this "knife-edge" mechanism does not work if there is any cost disturbance because the probability of incurring an extreme penalty becomes positive and makes the firm unwilling to participate. To implement this optimal solution in the more general case of cost disturbance, we must find a transfer function $t(\beta, C)$ that is such that:

$$
\left[\hat{\beta}, e^{*}(\hat{\beta})\right] \in \underset{\beta, e}{\operatorname{argmax}}\left\{E_{\epsilon}\{t[\beta,(\hat{\beta}-e) q(\beta)+\epsilon]\}+\delta\left[q(\beta)-q_{\text {ref }}\right]-\psi(e)\right\}
$$

and

$$
E_{\epsilon}\left\{t\left\{\hat{\beta},\left[\hat{\beta}-e^{*}(\hat{\beta})\right] q^{*}(\hat{\beta})+\epsilon\right\}\right\}=t^{*}(\hat{\beta})
$$

These conditions are satisfied by the following transfer function, linear in observed cost:

$$
t(\beta, C)=t^{*}(\beta)+K^{*}(\beta)\left[C^{*}(\beta)-C\right], \text { with } K^{*}(\beta)=\frac{\psi^{\prime}\left[e^{*}(\beta)\right]}{q^{*}(\beta)} .
$$

If the observed cost is higher (lower) than expected, $C>C^{*}(\beta)$, the government reimburses (receives) a fraction of the difference, $1-K^{*}(\beta)$, while the firm supports the remaining fraction, $K^{*}(\beta)$. The payment scheme is, then, composed by a fixed payment, $C^{*}(\hat{\beta})$, plus a partial cost reimbursement, $\left[1-K^{*}(\beta)\right]\left[C^{*}(\beta)-C\right]$.

\section{Proposition 1.}

Under Assumption 1, the optimal incentive compatible allocation, $\left[q^{*}(\hat{\beta}), e^{*}(\hat{\beta}), t^{*}(\hat{\beta})\right]$, can be implemented by a payment scheme that is linear in observed cost, $t(\beta, C)$.

Proof. Follow the steps in Laffont and Tirole (1986).

As in Laffont and Tirole (1986), the linear scheme implements the optimal allocation and it is the only contract that implements the optimal allocation for any probability distribution of the cost disturbance.

We find that, as in the case of complete information, the optimal level of output, $q^{*}$, and the optimal level of effort, $e^{*}$, are decreasing functions of the intrinsic marginal cost, $\hat{\beta}$. The more efficient is the firm, the higher are the output and the effort (see Appendix A.2.2). 
We also find that the optimal levels of effort and output are increasing with the manager's marginal utility of output, $\delta$. As in the case of complete information, this effect is smaller if $k=1$, and disappears when $k=1$ and $\lambda \rightarrow 0$.

\section{Lemma 4.1.}

The output and the effort, $q^{*}(\hat{\beta})$ and $e^{*}(\hat{\beta})$, increase with the preference for empire-building component, $\delta$.

Proof. See Appendix B.1.

As in the case of complete information, the taste for empire-building increases social welfare whenever the expected output level is larger than the reference output.

\section{Lemma 4.2 .}

The expected social welfare, $W^{*}$, increases (decreases) with the preference for empirebuilding, $\delta$, if and only if the expected output, $\int_{\underline{\beta}}^{\bar{\beta}} q^{*}(\hat{\beta}) d \hat{\beta}$, is larger (lower) than the reference output, $q_{\text {ref }}$.

Proof. See Appendix B.1.

We conclude that, under adverse selection and moral hazard, the effects of the empirebuilding bias are qualitatively the same as in the case of complete information.

Regarding the optimal contract, we find that the power of the optimal incentive scheme, that is, the fraction of the cost that is supported by the firm, $K^{*}$, is increasing with the

preference for empire-building, $\delta$, for any value of the intrinsic marginal cost, $\hat{\beta}$ (if $\psi^{\prime \prime \prime}$ is small enough).

The preference for empire-building is shown to countervail both the adverse selection and the moral hazard problem. Firms tend to announce a high intrinsic cost (adverse selection) in order to achieve the required efficiency with a low effort. Since the government assigns a lower output to firms that announce a high intrinsic cost, this tendency is decreasing with the manager's taste for empire-building. The preference for empire-building leads to a more powered incentive scheme because the output is higher (and, therefore, the benefits associated with effort are greater) and also because of this reduction in the problem of 
adverse selection. To understand this second effect, notice that as the power of the incentive scheme increases, the gain associated with an observed cost that is lower than expected increases. Therefore, the firm has an increased tendency to announce a high intrinsic cost (in order to lower the government's expectations). Adverse selection limits, in this sense, the power of the incentive scheme. The problem of moral hazard is, therefore, also mitigated by the empire-building bias.

\section{Lemma 4.3.}

For small enough $\psi^{\prime \prime \prime}$, the fraction of cost that is supported by the firm, $K^{*}(\hat{\beta})$, is increasing with $\delta$. That is: $\frac{d K^{*}(\hat{\beta})}{d \delta}>0$.

Proof. See Appendix B.1.

The role of $\psi^{\prime \prime \prime}$ is more subtle. From the incentive compatibility condition (6), a higher $\psi^{\prime \prime}$ implies that the information rent varies more with $\hat{\beta}$. The problem of adverse selection is, therefore, aggravated. This is why the power of the incentive scheme, $K^{*}$, is decreasing with $\psi^{\prime \prime}$. A stronger taste for empire-building induces a higher effort, and, if $\psi^{\prime \prime \prime}$ is large, an increase in $\psi^{\prime \prime}$ that dominates the previously mentioned effects, leading to a less powered incentive scheme.

\section{Concluding remarks}

We have studied procurement contracts between the government (principal) and the manager of a firm (agent) who has a preference for empire-building, in the presence of moral hazard and adverse selection. We found that the taste for empire-building leads to a higher level of public good provision and to a higher effort level. The optimal contract is shown to remain linear in observed cost but becomes more powered (the firm supports a higher fraction of the costs) when the manager has a stronger taste for empire-building. Welfare improves if and only if the expected output is higher than the output reference level of the managers.

The empire-building bias is shown to attenuate the adverse selection and moral hazard problem. The tendency to announce a low productivity is lower when the taste for empirebuilding is higher (because the government assigns a lower output to a firm that is less 
productive). We have explained why this allows a more powered incentive scheme (a lower fraction of the costs is reimbursed), which reduces the problem of moral hazard.

The strength of the manager's preference for higher output is, in the present model, known by the regulator. It would be interesting to account for the fact that it is more likely to be his/her private information and to analyze the resulting equilibrium in such a framework. This will be the subject of further research.

\section{A Appendix: Solving the model}

\section{A.1 The case of complete information}

Using (1), problem (2) can be written as:

$$
\max _{q, e, U}\left\{S(q)-(1+\lambda)\left[U-\delta\left(q-q_{r e f}\right)+\psi(e)+(\hat{\beta}-e) q\right]+U-k \delta\left(q-q_{r e f}\right)\right\}
$$

subject to

$$
U \geq 0
$$

With $\lambda>0$, the participation constraint is binding $(U=0)$.

The first order conditions of problem (9) are:

$$
\begin{gathered}
S^{\prime}(q)=(1+\lambda)(\hat{\beta}-e-\delta)+k \delta, \\
\psi^{\prime}(e)=q .
\end{gathered}
$$

The second order conditions of problem (9) are: ${ }^{8}$

$$
\begin{aligned}
& S^{\prime \prime}(q)<0, \\
& \psi^{\prime \prime}(e)>0, \\
& S^{\prime \prime}(q) \psi^{\prime \prime}(e)+(1+\lambda)<0 .
\end{aligned}
$$

By inspection of the first order conditions (10) and (11), we find that output, $q_{c}^{*}$, and effort, $e_{c}^{*}$, are decreasing functions of $\hat{\beta}$ and increasing functions of $\delta$.

$$
{ }^{8} \text { Corresponding to } \frac{\partial^{2} f}{\partial q^{2}}<0, \frac{\partial^{2} f}{\partial e^{2}}<0 \text { and } \frac{\partial^{2} f}{\partial q^{2}} \frac{\partial^{2} f}{\partial e^{2}}<\left(\frac{\partial^{2} f}{\partial q \partial e}\right)^{2} \text {. }
$$


To see how the social welfare, $W_{c}^{*}$, varies with the empire-building component, $\delta$, apply the Envelope Theorem:

$$
\frac{d W_{c}^{*}}{d \delta}=\left.\frac{\partial W_{c}}{\partial \delta}\right|_{q=q_{c}^{*}}=(1+\lambda-k)\left(q_{c}^{*}-q_{r e f}\right)
$$

\section{A.2 The optimal incentive scheme}

\section{A.2.1 The problem of the firm}

We start by analyzing the case in which there is no cost disturbance $(\epsilon=0)$.

Truthful behavior implies a total cost given by $C(\beta)=[\beta-e(\beta)] q(\beta)$. If the observed cost, $C=[\hat{\beta}-e] q(\beta)$, is different, the government imposes an extreme penalty to the firm (knife-edge mechanism):

$$
C \neq C(\beta) \Rightarrow t(\beta, C)=-\infty
$$

Still, a firm with cost $\hat{\beta}$ can claim to have a higher cost, $\beta>\hat{\beta}$, and choose a lower level of effort, $e<e(\beta)$, such that $C=C(\beta)$. In this case, the firm's deviation is concealed. Such level of effort is $e(\beta, \hat{\beta})=e(\beta)+\hat{\beta}-\beta$, and the resulting net transfer is $s(\beta)=t[\beta, C(\beta)]$.

For any $\hat{\beta} \in[\underline{\beta}, \bar{\beta}]$, truthful revelation must maximize the utility of the firm (3):

$$
\hat{\beta} \in \underset{\beta \in[\underline{\beta}, \bar{\beta}]}{\operatorname{argmax}} U(\beta, \hat{\beta})=\underset{\beta \in[\underline{\beta}, \bar{\beta}]}{\operatorname{argmax}}\left\{s(\beta)+\delta\left[q(\beta)-q_{\text {ref }}\right]-\psi[e(\beta)+\hat{\beta}-\beta]\right\} .
$$

Let $V(\hat{\beta})$ be the value function of the firm's maximization problem:

$$
V(\hat{\beta})=\max _{\beta \in[\underline{\beta}, \bar{\beta}]} U(\beta, \hat{\beta})=\max _{\beta \in[\underline{\beta}, \bar{\beta}]}\left\{s(\beta)+\delta\left[q(\beta)-q_{r e f}\right]-\psi[e(\beta)+\hat{\beta}-\beta]\right\} .
$$

From the Envelope Theorem, we obtain the first order incentive compatibility constraint: ${ }^{9}$

$$
V^{\prime}(\hat{\beta})=-\psi^{\prime}[e(\hat{\beta})]
$$

\footnotetext{
${ }^{9}$ The incentive compatibility condition (12) implies that the effort function, $e(\beta)$, and the utility function, $V(\hat{\beta})$, are differentiable almost everywhere (Laffont and Tirole, 1986).
} 
The local second order condition, $\left.\frac{\partial^{2} U(\beta, \hat{\beta})}{\partial \beta^{2}}\right|_{\beta=\hat{\beta}}<0$, holds if (Laffont and Tirole, 1986):

$$
e^{\prime}(\hat{\beta})<1 \text {. }
$$

The incentive compatibility condition (12) is equivalent to the first and second order conditions, (6) and (7). ${ }^{10}$

\section{A.2.2 The problem of the government}

We start by studying the following relaxed problem in which the second order incentive compatibility condition (7) is ignored (later, we shall check that this condition holds):

$$
\begin{array}{r}
\max _{q(\hat{\beta}), e(\hat{\beta}), V(\hat{\beta})} \int_{\underline{\beta}}^{\bar{\beta}} S[q(\hat{\beta})]-(1+\lambda)\left\{V(\hat{\beta})-\delta\left[q(\hat{\beta})-q_{r e f}\right]+\psi[e(\hat{\beta})]\right\}- \\
-(1+\lambda)[\hat{\beta}-e(\hat{\beta})] q(\hat{\beta})+V(\hat{\beta})-k \delta\left[q(\hat{\beta})-q_{\text {ref }}\right] d \hat{\beta}
\end{array}
$$

subject to

$$
\begin{gathered}
V(\bar{\beta})=0, \\
V^{\prime}(\hat{\beta})=-\psi^{\prime}[e(\hat{\beta})] .
\end{gathered}
$$

This is an optimal control problem with state variable $V(\hat{\beta})$ and control variables $e(\hat{\beta})$ and $q(\hat{\beta})$. The first order conditions are:

$$
\begin{gathered}
V(\bar{\beta})=0, \\
V^{\prime}(\hat{\beta})=-\psi^{\prime}[e(\hat{\beta})], \\
S^{\prime}[q(\hat{\beta})]=(1+\lambda)[\hat{\beta}-e(\hat{\beta})-\delta]+k \delta, \\
\psi^{\prime}[e(\hat{\beta})]=q(\hat{\beta})-\frac{\lambda}{1+\lambda}(\hat{\beta}-\underline{\beta}) \psi^{\prime \prime}[e(\hat{\beta})] .
\end{gathered}
$$

This relaxed problem (13) has a unique interior optimum (Laffont and Tirole, 1986).

\footnotetext{
${ }^{10}$ See Laffont and Tirole (1986).
} 
To check that the omitted condition (7) is satisfied, differentiate equations (15) and (16) with respect to $\hat{\beta}$ (we use simplified notation, below, for simplicity of exposition):

$$
\left\{\begin{array} { l } 
{ S ^ { \prime \prime } q ^ { * ^ { \prime } } = ( 1 + \lambda ) ( 1 - e ^ { * ^ { \prime } } ) } \\
{ \psi ^ { \prime \prime } e ^ { * ^ { \prime } } = q ^ { * ^ { \prime } } - \frac { \lambda } { 1 + \lambda } [ \psi ^ { \prime \prime } + ( \hat { \beta } - \underline { \beta } ) \psi ^ { \prime \prime \prime } e ^ { * ^ { \prime } } ] }
\end{array} \Leftrightarrow \left\{\begin{array}{l}
q^{*^{\prime}}=\frac{1+\lambda}{S^{\prime \prime}}\left(1-e^{*^{\prime}}\right) \\
e^{*^{\prime}}=\frac{1+\lambda-\left(\frac{\lambda}{1+\lambda}\right) S^{\prime \prime} \psi^{\prime \prime}}{S^{\prime \prime} \psi^{\prime \prime}+1+\lambda+\frac{\lambda}{1+\lambda}(\hat{\beta}-\underline{\beta}) S^{\prime \prime} \psi^{\prime \prime \prime}} .
\end{array}\right.\right.
$$

Using Assumption 1, we find that $e^{*^{\prime}}<0$ and $q^{*^{\prime}}<0$, implying that (7) is verified. The solution of the relaxed problem (13) also solves the problem of the government (4).

The equilibrium transfer is such that:

$$
t^{*}(\hat{\beta})=V(\hat{\beta})-\delta\left[q^{*}(\hat{\beta})-q_{\text {ref }}\right]+\psi\left[e^{*}(\hat{\beta})\right] .
$$

Integrating (6), we obtain:

$$
V(\hat{\beta})=V(\bar{\beta})+\int_{\hat{\beta}}^{\bar{\beta}} \psi^{\prime}[e(\gamma)] d \gamma
$$

Then:

$$
t^{*}(\hat{\beta})=\int_{\hat{\beta}}^{\bar{\beta}} \psi^{\prime}\left[e^{*}(\gamma)\right] d \gamma-\delta\left[q^{*}(\hat{\beta})-q_{r e f}\right]+\psi\left[e^{*}(\hat{\beta})\right]
$$

If $k$ increases, output and effort decrease, and the utility of the firm also decreases. From (16), we find that if $\psi^{\prime \prime \prime}$ is sufficiently small, $q^{*}(\hat{\beta})$ and $e^{*}(\hat{\beta})$ move in the same direction. From $(15), q^{*}(\hat{\beta})$ and $e^{*}(\hat{\beta})$ must be decreasing when $k$ increases. From $(14)$ and $(6)$ together with convexity of $\psi$, the decrease in $e^{*}(\hat{\beta})$ implies a decrease in $V^{*}(\hat{\beta})$.

\section{B Appendix: Effect of the empire-building compo- nent}

\section{B.1 The optimal incentive scheme}

Proof of Lemma 4.1.

Differentiating equations (15) and (16), in order to $\delta$ we obtain:

$$
\left\{\begin{array}{l}
S^{\prime \prime} \frac{d q^{*}(\hat{\beta})}{d \delta}=-(1+\lambda)\left(\frac{d e^{*}(\hat{\beta})}{d \delta}+1\right)+k \\
\psi^{\prime \prime} \frac{d e^{*}(\hat{\beta})}{d \delta}=\frac{d q^{*}(\hat{\beta})}{d \delta}-\left(\frac{\lambda}{1+\lambda}\right)(\hat{\beta}-\underline{\beta}) \psi^{\prime \prime \prime} \frac{d e^{*}(\hat{\beta})}{d \delta}
\end{array} \Leftrightarrow\right.
$$




$$
\begin{gathered}
\Leftrightarrow\left\{\begin{array}{l}
\frac{d q^{*}(\hat{\beta})}{d \delta}=-\frac{1+\lambda}{S^{\prime \prime}}\left(\frac{d e^{*}(\hat{\beta})}{d \delta}+1\right)+\frac{k}{S^{\prime \prime}} \\
\frac{d e^{*}(\hat{\beta})}{d \delta}=\frac{-\frac{1+\lambda}{S^{\prime \prime}}+\frac{k}{S^{\prime \prime}}}{\psi^{\prime \prime}+\frac{1+\lambda}{S^{\prime \prime}}+\left(\frac{\lambda}{1+\lambda}\right)(\hat{\beta}-\underline{\beta}) \psi^{\prime \prime \prime}}
\end{array} \Leftrightarrow\right. \\
\Leftrightarrow\left\{\begin{array}{l}
\frac{d q^{*}(\hat{\beta})}{d \delta}=\frac{1+\lambda}{S^{\prime \prime}}\left[\frac{1+\lambda-k}{\psi^{\prime \prime} S^{\prime \prime}+1+\lambda+S^{\prime \prime}\left(\frac{\lambda}{1+\lambda}\right)(\hat{\beta}-\underline{\beta}) \psi^{\prime \prime \prime}}-1\right] . \\
\frac{d e^{*}(\hat{\beta})}{d \delta}=-\frac{1+\lambda-k}{\psi^{\prime \prime} S^{\prime \prime}+1+\lambda+S^{\prime \prime}\left(\frac{\lambda}{1+\lambda}\right)(\hat{\beta}-\underline{\beta}) \psi^{\prime \prime \prime}}
\end{array}\right.
\end{gathered}
$$

Using Assumption 1 (i) and (ii), we find that $\frac{d e^{*}(\hat{\beta})}{d \delta}>0$ and $\frac{d q^{*}(\hat{\beta})}{d \delta}>0$ (with $\left.0 \leq k \leq 1\right)$.

Proof of Lemma 4.2.

The expected social welfare function is given by:

$$
\begin{array}{r}
W^{*}=\int_{\underline{\beta}}^{\bar{\beta}} S\left[q^{*}(\hat{\beta})\right]-(1+\lambda)\left\{-\delta\left[q^{*}(\hat{\beta})-q_{r e f}\right]+\psi\left[e^{*}(\hat{\beta})\right]+\left[\hat{\beta}-e^{*}(\hat{\beta})\right] q^{*}(\hat{\beta})\right\}+ \\
-\lambda V^{*}(\hat{\beta})-k \delta\left[q^{*}(\hat{\beta})-q_{r e f}\right] d \hat{\beta} .
\end{array}
$$

The problem is subject to $V^{* *}(\hat{\beta})=-\psi^{\prime}\left[e^{*}(\hat{\beta})\right]$. Integrating by parts:

$$
\int_{\underline{\beta}}^{\bar{\beta}} V^{*}(\hat{\beta}) d \hat{\beta}=\left[V^{*}(\hat{\beta})(\hat{\beta}-\underline{\beta})\right]_{\underline{\beta}}^{\bar{\beta}}+\int_{\underline{\beta}}^{\bar{\beta}} \psi^{\prime}\left[e^{*}(\hat{\beta})\right](\hat{\beta}-\underline{\beta}) d \hat{\beta} .
$$

Since $V(\bar{\beta})=0$, we have $\left[V^{*}(\hat{\beta})(\hat{\beta}-\underline{\beta})\right]_{\underline{\beta}}^{\bar{\beta}}=0$.

Rewriting the problem (18):

$$
\begin{array}{r}
W^{*}=\int_{\underline{\beta}}^{\bar{\beta}} S\left[q^{*}(\hat{\beta})\right]-(1+\lambda)\left\{-\delta\left[q^{*}(\hat{\beta})-q_{r e f}\right]+\psi\left[e^{*}(\hat{\beta})\right]+\left[\hat{\beta}-e^{*}(\hat{\beta})\right] q^{*}(\hat{\beta})\right\}+ \\
-\lambda \psi^{\prime}\left[e^{*}(\hat{\beta})\right](\hat{\beta}-\underline{\beta})-k \delta\left[q^{*}(\hat{\beta})-q_{r e f}\right] d \hat{\beta} .
\end{array}
$$

Using the Envelope Theorem we find:

$$
\frac{d W^{*}}{d \delta}=(1+\lambda-k) \int_{\underline{\beta}}^{\bar{\beta}}\left[q^{*}(\hat{\beta})-q_{r e f}\right] d \hat{\beta} .
$$


Proof of Lemma 4.3.

We know that both $e^{*}(\hat{\beta})$ and $q^{*}(\hat{\beta})$ are increasing in $\delta$. Using equation (16) we can rewrite (8) as:

$$
K^{*}(\hat{\beta})=1-\frac{\left(\frac{\lambda}{1+\lambda}\right)(\hat{\beta}-\underline{\beta}) \psi^{\prime \prime}\left[e^{*}(\hat{\beta})\right]}{q^{*}(\hat{\beta})} .
$$

Therefore:

$$
\frac{d K^{*}(\hat{\beta})}{d \delta}=-\left(\frac{\lambda}{1+\lambda}\right)(\hat{\beta}-\underline{\beta}) \frac{\psi^{\prime \prime \prime}\left[e^{*}(\hat{\beta})\right] \frac{d e^{*}(\hat{\beta})}{d \delta} q^{*}(\hat{\beta})-\frac{d q^{*}(\hat{\beta})}{d \delta} \psi^{\prime \prime}\left[e^{*}(\hat{\beta})\right]}{q^{*}(\hat{\beta})^{2}} .
$$

Thus, $\frac{d K^{*}(\hat{\beta})}{d \delta}>0$ if and only if:

$$
\psi^{\prime \prime \prime}\left[e^{*}(\hat{\beta})\right] \frac{d e^{*}(\hat{\beta})}{d \delta} q^{*}(\hat{\beta})-\frac{d q^{*}(\hat{\beta})}{d \delta} \psi^{\prime \prime}\left[e^{*}(\hat{\beta})\right]<0 \Leftrightarrow \frac{\frac{d q^{*}(\hat{\beta})}{d \delta}}{\frac{d e^{*}(\hat{\beta})}{d \delta}}>\frac{\psi^{\prime \prime \prime}\left[e^{*}(\hat{\beta})\right] q^{*}(\hat{\beta})}{\psi^{\prime \prime}\left[e^{*}(\hat{\beta})\right]} .
$$

From the expressions for $\frac{d q^{*}(\hat{\beta})}{d \delta}$ and $\frac{d e^{*}(\hat{\beta})}{d \delta}$ in Lemma 7, the condition above is always true when $\psi^{\prime \prime \prime}$ is null. Therefore, we may conclude that, in this case, $K^{*}(\hat{\beta})$ is increasing in $\delta$ for any value of $\hat{\beta}$.

\section{REFERENCES}

Arya, A., T. Baldenius and J. Glover (1999). 'Residual Income, Depreciation, and Empire Building', Working Paper.

Amihud, Y. and J. Kamin (1979). 'Revenue vs. Profit Maximization: Differences in Behavior by the Type of Control and by Market Power', Southern Economic Journal, Vol. 45, No 3, pp. 838-846.

Baron, D.P. and D. Besanko (1984). 'Regulation, Asymmetric Information and Auditing', Rand Journal of Economics, Vol. 15, pp. 447-470.

Baron, D.P. and R.B. Myerson (1982). 'Regulating a Monopolist with Unknown Costs', Econometrica, Vol. 50, No 4, pp. 911-930. 
Baumol, W.J. (1958). 'On the Theory of Oligopoly', Economica, Vol. 25, No 99, pp. 187-198.

Baumol, W.J. (1959). 'Business Behavior, Value and Growth', New York: Macmillan.

Baumol, W.J. (1977). 'Economic Theory and Operations Analysis', 4th ed., Englewood Cliffs, N.J.: Prentice-Hall.

Brehm, J. and S. Gates (1997). 'Working, Shirking, and Sabotage: Bureaucratic Response to a Democratic Public', University of Michigan Press.

Brown, J.R., N. Liang and S. Weisbenner (2007). 'Executive Financial Incentives and Payout Policy: Firm Responses to the 2003 Dividend Tax Cut', Journal of Finance, Vol. 62, No 4, pp. 1935-1965.

Chetty, R. and E. Saez (2005). 'Dividend Taxes and Corporate Behavior: Evidence from the 2003 Dividend Tax Cut', Quarterly Journal of Economics, Vol. 120, No 3, pp. 791-833.

Chiang, A.C. and K. Wainwright (2005). 'Fundamental Methods of Mathematical Economics', Fourth edition, Boston: McGraw-Hill.

Donaldson, G. (1984). 'Managing corporate wealth', New York: Praeger.

Fershtman, C. and K.L. Judd (1987). 'Equilibrium Incentives in Oligopoly', The American Economic Review, Vol. 77, No 5, pp. 927-940.

Grossman, S. and O. Hart (1988). 'One shareone vote and the market for corporate control', Journal of Financial Economics, Vol. 20, pp. 175-202.

Guesnerie, R. and J.-J. Laffont (1984). 'A complete solution to a class of principal-agent problems with an application to the control of a self-managed firm', Journal of Public Economics, Vol. 25, pp. 329-369.

Harris, M. and A. Raviv (1996). 'The Capital Budgeting Process: Incentives and Information', Journal of Finance, Vol. 51, pp. 1139-1174.

Hart, O. and J. Moore (1995). 'Debt and seniority : An analysis of the role of hard claims in constraining management', American Economic Review, Vol. 85, No 3, pp. 567-585. 
Jensen, M.C. (1986). 'Agency costs of free cash flow, corporate finance and take-overs', American Economic Review, Vol. 76, No 2, pp. 3323-329.

Jensen, M.C., (1993). 'The modern industrial revolution, exit, and the failure of internal control systems', Journal of Finance, Vol. 48, pp. 831-880.

Kanniainen, V. (2000). 'Empire building by corporate managers: The corporation as a savings instrument', Journal of Economic Dynamics and Control, Vol. 24, pp. 127-142.

Laffont, J.-J. and J. Tirole (1986). 'Using Cost Observation to Regulate Firms', Journal of Political Economy, Vol. 94, No 3, pp. 614-641.

Laffont, J.-J. and J. Tirole (1993). 'A Theory of Incentives in Procurement and Regulation', Cambridge: MIT Press.

Li, D.D. and S. Li (1996). 'A Theory of Corporate Scope and Financial Structure', Journal of Finance, Vol. 51, No 2, pp. 691-709.

Marris, R. (1963). 'A Model of the 'Managerial' Enterprise', Quarterly Journal of Economics, Vol. 77, No 2, pp. 185-209.

Marris, R. (1964). 'The Economic Theory of Managerial Capitalism', New York: Macmillan.

Maskin, E. and J. Riley (1984). 'Monopoly with incomplete information', RAND Journal of Economics, Vol. 15, No 2, pp. 171-196.

McGuire, J.W., Chiu, J.S.Y. and A.O. Elbing (1962). 'Executive Incomes, Sales and Profits', American Economic Review, Vol. 52, No 4, pp. 753-761.

Monsen, R.J. and A. Downs (1965). 'A Theory of Large Managerial Firms', Journal of Political Economy, Vol. 73, No 3, pp. 221-236.

Mueller, D.C. (2003). 'Public Choice III', Cambridge: Cambridge University Press.

Myerson, R.B. (1979). 'Incentive Compatibility and the Bargaining Problem', Econometrica, Vol. 47, No 1, pp. 61-74.

Niskanen, W.A. (1971). 'Bureaucracy and Representative Government', Chicago: AldineAtherton. 
Prendergast, E. (2007). 'The Motivation and Bias of Bureaucrats', American Economic Review, Vol. 97, No 1, pp. 180-196.

Sklivas, S.D. (1987). 'The Strategic Choice of Managerial Incentives', The RAND Journal of Economics, Vol. 18, No 3, pp. 452-458.

Stulz, R.M. (1990). 'Managerial Discretion and Optimal Financing Policies', Journal of Financial Economics, Vol. 26, pp. 3-27.

Williamson, O.E. (1963). 'Managerial Discretion and Business Behavior', American Economic Review, Vol. 53, pp. 1032-1057.

Williamson, O.E. (1974). 'The Economics of Discretionary Behavior: Managerial Objectives in a Theory of the Firm', London: Academic Book Publishers.

Wilson, J.Q. (1989). 'Bureaucracy: What Government Agencies Do and Why They Do It', New York: Basic Books.

Zwiebel, J. (1996). 'Dynamic capital structure under management entrenchment', American Economic Review, Vol. 86, No 5, pp. 1197-1215. 